\title{
ДОБРОСОВЕСТНОСТЬ, РАЗУМНОСТЬ И СПРАВЕДЛИВОСТЬ В СОВРЕМЕННОМ ГРАЖДАНСКОМ ПРАВЕ
}

Развитие гражданского права на современном этапе характеризуется возвратом к классическим морально-этическим основам частного права. Переосмысление их роли и значения позволяет предопределить дальнейшее развитие всего гражданского права. Категории добросовестности, разумности и справедливости традиционно относят к классическим оценочным понятиям частного права. Благодаря их существованию гражданско-правовое регулирование приобретает необходимую гибкость, так как суд при их применении имеет возможность учитывать обстоятельства конкретного дела. Одновременно с этим, использование оценочных категорий связано с определенням субъективизму при применении и толковании соответствующих норм права. Кроме того, с расширением сферы частноправового регулирования, возрастает и степень неопределенности норм гражданского права, призванных регулировать постоянно меняющиеся общественные отношения, а также устранять пробелы и коллизии гражданско-правового регулирования. Исследованию вопроса применения оценочных понятий посвящены труды С. Алексеева, В. Асмуса, В. Биленко, И. Бабич, А.Васильева, В. Жеребкина, И. Зайцевой, Т. Коломоец, В. Косовича, П. Лютикова, Д. Павленко, В. Примака, И. Титко, И. Турчин-Кукариной, и др. Среди современных российских исследователей выделяются труды: Е. Богданова, Е. Богдановой, Ю. Виниченко, В. Грибанова, Т. Дроздовой, Д. Левиной, С. Ивановой, М. Лукьяненко, Г. Нигматдинова, А. Малиновского, Л. Щенниковой. В украинской правовой науке вопрос применения категорий, добросовестности, разумности и справедливости в гражданском праве остается недостаточно исследованным, но очень актуальным, учитывая то, что эти понятия все чаще используются пол регулировании хозяйственных, жилищных, семейных правоотношений, определяя содержание защиты прав и законных интересов их участников. 
Целью статьи является исследование особенностей определения содержания «классических» оценочных понятий гражданского права, таких как добросовестность, разумность и справедливость.

Анализ норм гражданского законодательства позволяет сделать вывод, что оно оперирует огромным количеством оценочных понятий, одни из которых получают развернутое определение, другие обозначаются одним термином, точный смысл которого не определен. При всей множественности оценочных понятий в гражданском праве, мы считаем, что наиболее распространенными оценочными понятиями украинского гражданского права являются понятия «добросовестность», «разумность», «справедливость». В соответствии с положениями ст. 12 Гражданского кодекса Украины (далее - ГК Украины) лицо осуществляет свои гражданские права свободно, и по своему усмотрению ... если законом установлены правовые последствия недобросовестного или неразумного осуществления лицом своего права, считается, что поведение лица является добросовестным и разумным, если иное не установлено судом. Таким образом, в действующем гражданском законодательстве установлена презумпция правомерности, добросовестности, разумности действий участников гражданских правоотношений.

В решении Конституционного суда Украины от 2.11.2004 г. № 15-рп/ 2004 отмечено, что согласно части первой статьи 8 Конституции Украины в Украине признается и действует принцип верховенства права. Верховенство права это господство права в обществе. Верховенство права требует от государства его воплощения в правотворческой и правозащитной деятельности, в частности законы должны быть проникнуты, прежде всего, идеями социальной справедливости, свободы и равенства. Одним из проявлений верховенства права является то, что право не ограничивается лишь законодательством как одной из его форм, а включает и другие социальные регуляторы, в частности нормы морали, традиции, обычаи и т.д., которые легитимированы обществом и обусловлены исторически достигнутым культурным уровнем общества. Все эти элементы права объединяются в соответствии с идеологией справедливости, идеей права, которая получила свое отражение в Конституции Украины. Такое понимание права не дает оснований для его отождествления с законом, который иногда может быть и несправедливым, в том числе ограничивать свободу и равенство лиц. Справедливость - один из основных принципов права, является одним из общечеловеческих измерений права ${ }^{1}$. Диспозитивность гражданского права проявляется в основополагающем его принципе - в принципе свободы договоров. Стороны свободны при заключении договора, выборе контрагентов и определении условий договора, но с учетом требова- 
ний актов гражданского законодательства, обычаев делового оборота, требований разумности и справедливости (ст. 627 ГК Украины) ${ }^{2}$. В гражданском праве справедливость принято относить к оценочным понятиям вместе с добросовестностью и разумностью. Появление оценочно-нравственных понятий в законодательных актах, созданных на этапе перехода к новым рыночным отношениям, свойственно не только украинской системе права. Эта закономерность характерна и для иностранных правопорядков. Так, Е. А. Фарневорт отмечает, что в США в период становления системы рыночного хозяйства отмечалось расширение использования более общих формулировок по сравнению с обычным законодательством США. Эта «нарочитая неопределенность» предоставила решающую роль судам в толковании законов и приспособлении их к меняющимся условиям рынка. Вместо того, чтобы устанавливать четкие и жесткие правила, законодатель призвал суды руководствоваться следующими общими, нравственными правилами, закрепленными в законе, как правила разумности, добросовестности и справедливости ${ }^{3}$. В цивилистике существует несколько позиций относительно характеристики категории справедливости. Так, Л. Щенникова считает, что принцип справедливости реализуется в принципах гражданского права ${ }^{4}$. Критерии реализации принципа справедливости в гражданском законодательстве находят свое отражение в ст. 3 ГК Украины. С. Иванова указывает, что принцип справедливости (как общий принцип права) нашел воплощение в принципах разумности и добросовестности (как отраслевых принципах права). Он «растворился» в огромном массиве гражданского законодательства, найдя свое выражение в понятиях разумности и добросовестности 5 . В. Белов, напротив, отмечает, что принцип добросовестности является обобщающим по отношению к принципам разумности и справедливости ${ }^{6}$. Признавая безусловную взаимосвязь между указанными понятиями, считаем, что их нужно рассматривать как самостоятельные. А понятие справедливости в гражданском праве, подчеркивая специфику гражданского права как частного, реализуется через основные принципы гражданско-правового регулирования, такие как равенство сторон, имущественная самостоятельность и автономия воли. Основные принципы гражданского законодательства, закрепленные в ст. 3 ГК Украины, являются основными элементами реализации понятия справедливости в гражданском праве. Соответственно нарушение

2 Бабич І.Г. Принцип справедливості в римському праві і у сучасному зобов'язальному праві України. - Дисс.к.ю.н. Одеса., 2008. - С. 49-50

3 Мозолин В. П., Фарневорт Е. А. Договорное право в США и СССР. История и общие тенденции. М.: Наука, 1988. - С. 13.

4 Щенникова Л. В. Справедливость и добросовестность в гражданском праве России (несколько вопросов теории и практики) // Государство и право. 1997. №. 6. С. 120.

5 Иванова С. А. Некоторые проблемы реализации принципа социальной справедливости, разумности и добросовестности в гражданском праве // Законодательство и экономика. 2005. № 4. - С. 31.

6 Белов В. А. Добросовестность, разумность, справедливость как принципы гражданского права // Законодательство. 1998. № 8. - С. 50. 
хотя бы одного из основных начал гражданского законодательства ведет к несоблюдению принципа справедливости в гражданском праве.

Категория добросовестности (bona fides) появилась в римском частном праве. При этом «bona fides» в объективном смысле касалась обязательств, а в субъективном - прав ${ }^{7}$. В то же время большинство исследователей указывают на то, что категория добросовестности является нравственной и поэтому пытаться жестко определить ее в законе, договоре или решении суда практически невозможно, а в отдельных случаях и не стоит. В частности, И. Покровский приводит такое высказывание немецкого исследователя Е. Эрлиха по поводу определения понятия добросовестности: «Что такое по немецкому праву злоупотребление правом, в каких случаях имеет место нарушение «Treu und Glauben», или« добрых нравов » - этого мы пока не знаем потому, что закон по этому поводу ничего не говорит, мы узнаем об этом только из судебных решений лет через сто» ${ }^{8}$. Б. Зеллер в результате своего исследования категории «добросовестность» пришел к выводу, что, несмотря на ее «соблазнительную простоту», добросовестность является неуловимым понятием ${ }^{9}$. И. Покровский анализируя понятие добросовестности выступал против значительного расширения этого понятия, в частности в судебных решениях, ссылаясь на то, что использование широкого подхода к определению понятия «добросовестность» может привести к полному судебному контролю всего гражданского оборота на основании субъективных и произвольных представлений о «справедливости», «социальных идеалах» и т.д ${ }^{10}$. Нужно отметить, что применение понятия добросовестности связано со сложившимся в обществе отношением к базовым морально-этическим категориям добра и зла, добросовестности-вины-недобросовестности. Категория «добросовестность» важна не только с точки зрения юридической техники, но и с точки зрения общественной морали, которая, развиваясь в условиях постоянной неопределенности и потери приоритетов, теряет базовый цивилизационный смысл.

И. Новицкий, анализируя подходы к определению понятия добросовестности, отмечал: «многочисленные случаи, когда гражданско-правовые нормы прямо или косвенно привлекают принципы доброй совести, можно свести к двум основным группам. В одних случаях добрая совесть выступает в объективном смысле, как известное внешнее мерило, которое принимается во внимание законом, судом, применяющим закон, и которое рекомендуется членам

Краснова С.А. Определение понятия «добросовестность» в российском гражданском праве // Журнал российского права. М. : 2003.- № 3.- С.6.

9 Zeller B. Good faith - The Scarlet Pimpernel of the CISG // [http: //www. cisg.law, pace.edu/cisg/biblio/zeller2. html.] 2000

Покровский И.А. Основные проблемы гражданского права. М.Статут. 1998., - С. 261 
гражданского оборота в их отношениях друг с другом ... В других случаях категория доброй совести воспринимается в субъективном смысле, как некое восприятие того или иного лица, его осведомленность или неосведомленность по поводу определенных обстоятельств, с которыми закон связывает те или иные юридические последствия» ${ }^{11}$.

Современные ученые пытаются совместить объективные и субъективные подходы к определению понятия «добросовестность». Е.Богданова отмечает, что под добросовестностью следует понимать такую систему представлений о нравственности, поведении при осуществлении и защите прав, исполнении обязанностей, которая сложилась в обществе и признана законом, обычаями или судебной практикой ${ }^{12}$.

М. Лукьяненко выделяет следующие признаки добросовестности: честность, искренность, сознание, исполнительность, аккуратность в выполнении гражданско-правовых обязанностей ${ }^{13}$. По нашему мнению, следует согласиться с тем, что понятие «добросовестность» имеет двоякий характер. В объективном смысле добросовестность представляет собой определенные нормами права, обычаями делового оборота требования предъявляемая, предявляемые к поведению неопределенного круга участников гражданских правоотношений. В субъективном смысле добросовестность это оценка поведения субъекта гражданских правоотношений в соответствии со сложившимися в обществе нормами морали, уважения к правам других участников правоотношений.

Развитие международного сотрудничества и гармонизация законодательства в сфере гражданско-правового оборота привела к формированию качественно новых подходов к закреплению содержания классических оценочных понятий гражданского права, таких как добросовестность, разумность и справедливость. Так, значительной вехой в развитии торгового права (lex mercatoria) стала разработка Принципов международных коммерческих договоров ${ }^{14}$. Ст. 1.7 Принципов приказывает: «Каждая сторона обязана действовать в соответствии с принятыми в практике международной торговли добросовестностью и честной деловой практикой».. Таким образом, добросовестность в данном акте предстает в качестве объективного стандарта, соотносимого с честной деловой практикой. Более того, согласно ст. 4.8, 5.9 Принципов добросовестность может использоваться как средство для определения содержания не закреплен-

11 Новицкий И.Б. Принцип доброй совести в проекте обязательственного права//Вестник Гражданского права. Петроград.-1916. - № 6-октябрь.

12 Богданова Е.Е. Добросовестность и право на защиту в договорных отношениях. М.: Закон и право. ЮНИТИ. 2010. - С. 26.

13 Лукьяненко М.Ф. Оценочные понятия гражданского права: разумность, добросовестность, существенность. М.: Статут. 2010. - 368-369

14 Принципы международных коммерческих договоров (Принципы УНИДРУА)// www.unidroit.org/.../ blackletter2010-russia.. 
ных в договоре условий или определения наличия обязательства. Важным шагом к созданию единообразной системы европейского договорного права стали Принципы Европейского договорного права (The Principles of European Contract law), созданные при поддержке Европарламента и Комиссии EC ${ }^{15}$. В Принципах европейского договорного права, составленных Оле Ландо, особое место отводится и принципу добросовестности (ст. 1:105). Предполагается, что каждая сторона обязана действовать в соответствии с этим принципом, и стороны не могут ограничить эту обязанность. Кроме того, стороны могут свободно заключать договоры и устанавливать их содержание согласно этому принципу (ст. 1:102). Следует отметить, что в Принципах часто встречается и понятие разумности, в частности, «разумное условие», «разумная сторона», «разумная цена» и т.п. Стоит отметить, что это понятие часто рассматривается как эквивалент добросовестности, особенно в праве Англии. В Принципах европейского договорного права, также содержится положение о том, что «разумность должна оцениваться, исходя из того, что лица действуют добросовестно в такой же ситуации, в которой их действия считаются разумными». Кроме того, как отмечается, «требование верности условиям договора, по сути, подчеркивает значение, которое придается добросовестности и разумности» ${ }^{16}$.

Понятие «разумность» в гражданском праве выступает как законодательное требование и как принцип права. И одновременно с этим, разумность рассматривается как начало права, т.е. первооснова права и как способность человека к мышлению и пониманию (интеллектуальность).

Л. Щенникова рассматривает разумность как требование законодательства ко всем участникам гражданских правоотношений, обязанных «руководствоваться в своих действиях умом» ${ }^{17}$. В. Молозин отмечает, что разумность - осознание правомерности своего поведения ${ }^{18}$. По мнению И. Емельянова, разумность - это интеллектуальная деятельность человека, характеризующая объективную сторону его действий. Однако, оценка действий лица осуществляется на основе сравнения действий участника гражданских правоотношений с поведением среднего разумного лица, поведение которого и выступает критерием для определения понятия «разумность» ${ }^{19}$. По нашему мнению, при осуществлении гражданских прав физические и юридические лица обяза-

Principles of European Contract Law. Parts I and II / Ed.: O. Lando,H. Beale. - The Hague ; London ; Boston : Kluwer Law,2000; Principles of European Contract Law. Part III / Ed.: O. Lando, E. Clive, A. Prum, R. Zimmerman. — The Hague ; London ; New York : Kluwer Law, 2003. Mazeaud D., Un droit européen en quête d'identité. Les principes du droit européen des contrats. Dalloz Chr. 2007. - $2962 \mathrm{p}$.

17 Щенникова Л. В. Справедливость и добросовестность в гражданском праве (несколько вопросов теории и практики) // Государство и право 1997. № 6. С. 119.

18 Комментарий к Гражданскому кодексу Российской Федерации, части первой. Под ред. Т.Е. Абовой, А.Ю. Кабалкина. М., 2002.- 1069 c. http://www.az-libr.ru/index.shtml?Law\&Civil/ru/GK2004Abova/gka000

19 Емельянов В. И. Недопустимость злоупотребления гражданскими нравами по российскому законодательству. Дисс. .... к. ю. Н.. - М., 2001.- С. 61-63 
ны соблюдать условия, установленные законом и иными правовыми предписаниями, то есть их поведение должно соответствовать моральным принципам общества (ст. 13, 19, 26, 319 , ГК Украины). По нашему мнению, следует согласиться с Ю. Виниченко, которая считает, что основным объективным критерием понятия разумности является целесообразность, а другим - пропорциональность $^{20}$. Однако при определении разумности поведения лица надо также учитывать его возраст, образование и другие факторы. Разумность относится к неимущественным благам, и является определением добра в праве. Несоблюдение требований разумности означает злоупотребление правом, т.е. использование права с намерением причинить вред другому лицу или умышленное нарушение установленной меры и границ при реализации собственной свободы, и использование права в ущерб другим участникам правоотношений. Согласно ст. 13 ГК Украины в случае неразумного осуществления субъективного гражданского права, т.е. в случае совершения неразумного действия, лицу может быть отказано в защите данного права.

Выводы. Гражданско-правовому регулированию присуще стремление к формальной определенности. Однако, современное гражданское законодательство не может учесть всех возможных ситуаций, требующих правового регулирования. Учитывая это, законодатель использует оценочные понятия, основанные на соответствующих правилах и обычаях, нормах морали, этических канонах, принятых в обществе. Закрепление в нормах действующего гражданского законодательства требований добросовестности, разумности является реализацией принципа справедливости. Требование справедливости в большинстве случаев в нормах ГК Украины презюмируется, что требует от субъекта гражданско-правовых отношений выбора справедливой, добросовестной и разумной модели поведения. Морально-этический характер рассматриваемых понятий предусматривает, что при их реализации участники гражданских правоотношений, а также лица, применяющие положения ГК Украины, содержащие ссылки на разумность и добросовестность, реализуют свои морально-этические представления о праве, справедливости и морали. По нашему мнению, решения независимого справедливого суда, обладающего высоким моральным авторитетом в обществе, могут стать основой для формирования унифицированной позиции по вопросу применения оценочных понятий в частном праве, в частности, таких как добросовестность, разумность и справедливость. 


\section{БИБЛИОГРАФИЯ}

1. Бабич І.Г. Принцип справедливості в римському праві і у сучасному зобов'язальному праві України. - Дисс.к.ю.н. Одеса., 2008.

2. Белов В. А. Добросовестность, разумность, справедливость как принципы гражданского права // Законодательство. 1998. № 8.

3. Емельянов В. И. Недопустимость злоупотребления гражданскими нравами по российскому законодательству. Дисс. .... к. ю. н.. - М., 2001.

4. Новицкий И.Б. Принцип доброй совести в проекте обязательственного права//Вестник Гражданского права. Петроград.-1916. - № 6-октябрь.

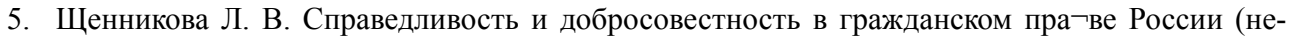
сколько вопросов теории и практики) // Государство и право. 1997. №. 6.

6. Иванова С. А. Некоторые проблемы реализации принципа социальной справедливости, раз-

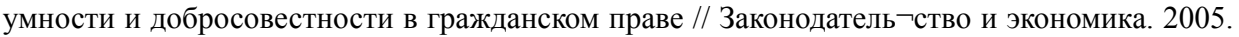
№ 4.

7. Комментарий к Гражданскому кодексу Российской Федерации, частипервой. Под ред. Т.Е. Абовой, А.Ю. Кабалкина. М., 2002.

8. Краснова С.А. Определение понятия «добросовестность» в российском гражданском праве // Журнал российского права. М. : 2003.- № 3.

9. Лукьяненко М.Ф. Оценочные понятия гражданского права: разумность, добросовестность, существенность. М.: Статут. 2010.

10. Mazeaud D., Un droit européen en quête d'identité. Les principes du droit européen des contrats. Dalloz Chr. 2007.

11. Мозолин В. П., Фарневорт Е. А. Договорное право в США и СССР. Исто-рия и общие тенденции. М.: Наука, 1988.

12. Новицкий И.Б. Принцип доброй совести в проекте обязательственного права//Вестник Гражданского права. Петроград.-1916. - № 6-октябрь.

13. Покровский И.А. Основные проблемы гражданского права. М.Статут. 1998.

14. Principles of European Contract Law. Parts I and II / Ed.: O. Lando,H. Beale. - The Hague ; London; Boston : Kluwer Law,2000.

15. Principles of European Contract Law. Part III / Ed.: O. Lando, E. Clive, A. Prum, R. Zimmerman. — The Hague ; London ; New York : Kluwer Law, 2003.

16. Виниченко Ю.В. Разумность в гражданском праве Российской Федерации: Дис. канд. юрид. наук. Иркутск, 2003. 
Добросовестность, разумность и справедливость в современном гражданском праве

\section{GOOD FAITH, REASONABLENESS AND FAIRNESS}

IN MODERN CIVIL LAW

The article describes the features of 'classical' assessment of the civil law concepts of good faith, reasonableness and fairness. This is determined by the theoretical and legal approaches to the specification and interpretation of the norms of international treaties.

Key words: evaluative categories, good faith, reasonableness, fairness 